\title{
the early history of weather modification
}

\section{Abstract}

Since ancient times man has dreamed of manipulating the weather to his advantage. His efforts to this end have ranged from drawing pictographs, lighting ceremonial fires, participating in rain dances and then during the past twenty-one years in directing his attention toward utilizing certain scientific relationships to initiate physical and chemical reactions in the atmosphere.

There are certain of these reactions which can be demonstrated in both the laboratory and the field. They are spectacular to see, are fairly well understood from the scientific viewpoint and can be used to produce definite and predictable reactions.

There no longer is any question that it is quite feasible to modify supercooled clouds wherever they occur. There is still much uncertainty as to subsequent developments which may occur due to such actions especially in unstable cloud systems. Unlike supercooled fogs and stratus clouds where the seeding results may be photographed and quantitatively measured, these less stable systems involving convection, convergence and divergence of moist and dry air are difficult systems to evaluate.

This paper reviews briefly certain aspects of weather control prior to 1946 and then attempts to provide an accurate historical chronology of the significant advances which occurred during the early period of this new phase of atmospheric science.

The control of the weather within our global atmosphere has been a dream of man for many centuries. In its earliest phases this ambition was limited to the rain needed for a tiny patch of corn or some similar local and immediate need. As man's knowledge of the atmosphere increased and his needs became more urgent and widespread, his approach to such problems were increasingly directed toward a scientific consideration of the possibilities as well as limitations of changing atmospheric processes.

Prior to 1946, all of the proposals advanced toward doing something about modifying atmospheric processes failed to consider the massive nature of the atmosphere and the need to depend on triggering mechanisms to utilize the latent energy which develops from some of the physical reactions and interactions which occur in clear and cloudy skies.

\section{Early references to the use of dry ice in the atmosphere}

Thus the ideas of Gathman in 1891 [1] and Veraart [2] in 1931 that dry ice could be used to produce clouds and subsequently rain failed to appreciate the dimensions of the atmosphere and that dry ice could be used to generate fantastic quantities of ice embryos if introduced into air colder than $0 \mathrm{C}$ and supersaturated with respect to ice.

The lack of appreciation of certain fundamental physical reactions in cloud physics is not limited to this early period. As recently as 1966 the National Academy Report [3] in referring to my initial discovery [4] of the effect produced by dry ice in a supercooled cloud implies that the dry ice seeding effect causes the freezing of supercooled droplets in a cloud. The effect of dry ice or any other mechanism which locally chills or otherwise produces homogeneous nucleation in air supersaturated with respect to ice at temperatures colder than $0 \mathrm{C}$ generates ice embryos by at least three or four orders of magnitude greater than the number of droplets in the affected cloud.

\section{The use of trigger effects in modifying atmospheric processes}

Findeisen was the first, to my knowledge, to recognize the importance of trigger effects in affecting atmospheric weather systems when he said [5],

"The recognition of the fact that quite minute, quantitatively inappreciable elements, are the actual cause setting into operation weather phenomena of the highest magnitude, gives the certainty that, in time, human science will be enabled to effect an artificial control on the course of meteorological phenomena. It would be going beyond the limits of the present work to discuss in detail the possibility of exercising a kind of technical control over the course of weather conditions. From the considerations under survey here, we have now come to quite new points of view on this. It can be boldly stated that, at comparatively moderate expense, it will, in time, be possible to bring about rain by scientific means, to obviate the danger of icing, and to prevent the formation of hailstorms. Through the energy transformations thus secured, various other weather phenomena (e.g. temperature, wind) will be brought under a certain kind of control, which perhaps never, in a direct manner, could, to an appreciable extent, be acted upon in the atmosphere. The 
colloido-meteorological investigations, by themselves with the only assistance of research work on the means to get some control over the weather factors, have opened up a new field for their efforts. They obviously only can solve those various problems with the close assistance of aerology."

\section{Details of the laboratory discovery of the dry ice effect}

My discovery that dry ice produces fantastic numbers of ice embryos, although a serendipitous event, was like so many similar happenings the by-product of an intensive effort to discover a material to nucleate supercooled clouds. The instant I put a chunk of dry ice into my cold chamber, I realized that my immediate search had ended.

Since there is much confusion in the current literature concerning the factors surrounding the discovery of the dry ice seeding technique, it is in order to describe that period accurately.

The chain of events which led to this discovery have been described in some detail in a paper published in 1960 [6]. This outlined briefly our work in surface chemistry [7], gas mask filters and artificial fog generators [8], precipitation static research [9] and finally aircraft icing studies [10] at the Mt. Washington Observatory. It was the latter two research projects which introduced us to the occurrence and anomaly of supercooled clouds in the atmosphere-the cause of aircraft icing. In this paper I neglected to mention the method I discovered on 31 January 1941 of replicating ice crystals and other evanescent substances $[11,12]$. The replication of ice crystals, fallen snow, cloud droplets and similar atmospheric substances first directed our research interests at General Electric toward atmospheric phenomena and has been a recurring factor in many of our efforts right up to the present time. In fact much of my laboratory and field research would be very difficult without the availability of this replication technique.

Early in 1946 one of my associates, Robert SmithJohannsen, managed to obtain a four cubic foot food

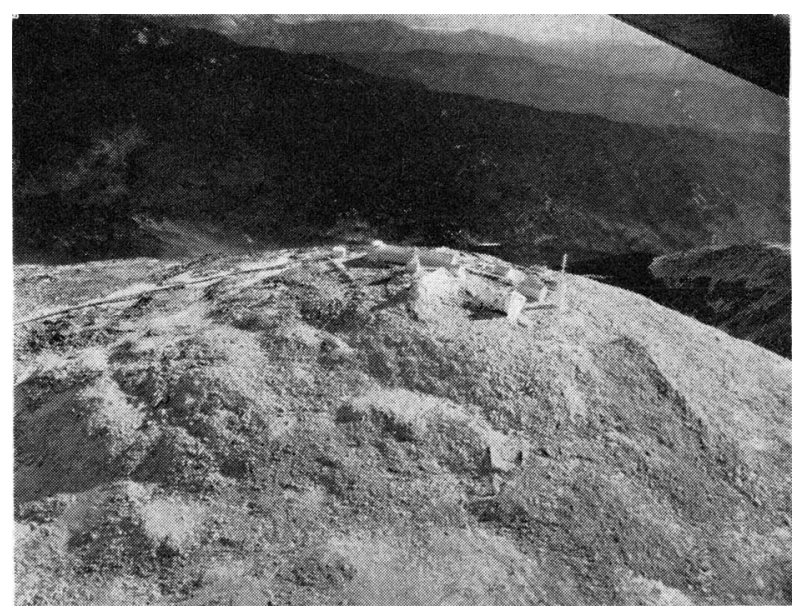

Mt. Washington Observatory used by G. E. Group between 1943-1954. freezer which was then being introduced as a post-war feature by General Electric. He planned to use it for testing the ice release properties of various types of ice cube trays and surface coatings. We had previously been using the summit of Mt. Washington as a site for such studies but needed a more convenient and available environment for such studies. It at once became apparent to me that such a chamber was ideal for my studies of supercooling. We began to share this four cubic foot cold area, but soon found it desirable to obtain another for our separate studies.

I soon found it necessary to provide a better contrast for viewing the reactions in the supercooled clouds I was producing so I had a wooden frame constructed on which was mounted black velvet cloth for the sides and bottom of the chamber. Incidentally, such a lining should be of semi-transparent rayon black velvet stretched taut on a wooden frame held $1 \mathrm{~cm}$ from the cold walls. With a strong beam of light to illuminate the clouds produced by exhaling my breath, I had an ideal environment for producing and experimenting with supercooled clouds down to a temperature of about $-25 \mathrm{C}$.

During the late spring of 1946 I tested a variety of chemicals selected from our well-stocked shelves, dusting them into the chamber with and without a supercooled cloud. I didn't have any appreciable success. Then early in July we had a period of hot weather with our laboratory becoming so warm as to affect the cooling capacity of my small chamber. I decided to use some dry ice to assist in cooling the chamber. The instant I put the dry ice into the supercooled cloud a spectacular change occurred in the supercooled cloud and I knew that I had achieved the transformation I had been seeking. I immediately showed the effect to Bob Johannsen and my other associate, Dr. Katharine Blodgett, as well as anyone else I could find in the laboratory to see this spectacular reaction. I found the most effective method

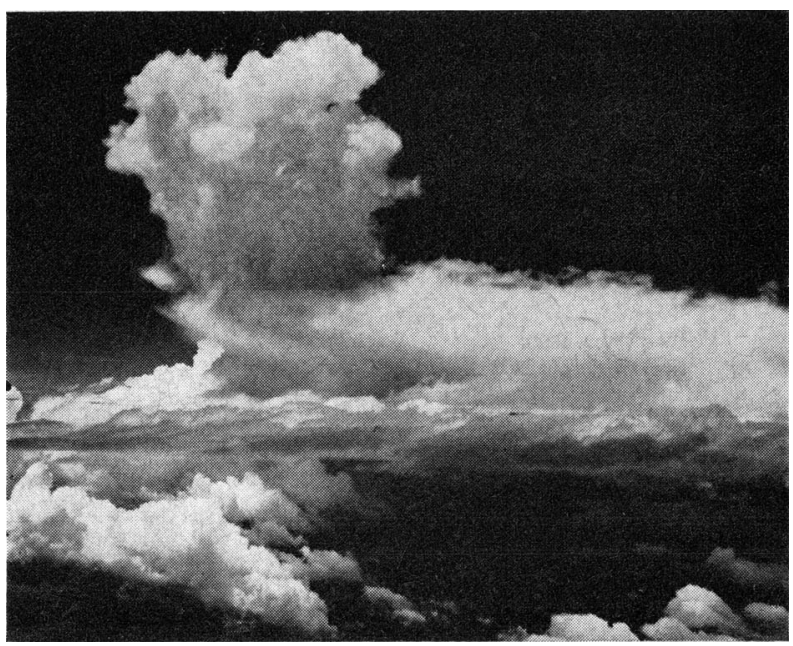

Effect of seeding cumulus cloud with $18 \#$ of dry ice. 
of introducing the dry ice was to scratch a chunk of it with a nail.

\section{Further laboratory and field activities in 1946}

Within the next few weeks I found that anything colder than -40C would produce the seeding effect. One of the most convenient techniques I found utilized an ordinary sewing needle suspended on a thread and cooled in liquid nitrogen. Drawn through a supercooled cloud, it produced the same type of reaction as dry ice.

When Dr. Langmuir returned from the West Coast where he had been giving a series of lectures at Cal Tech, he immediately recognized the implications of the dry ice effect and made it possible for me to extend my studies into the atmospheric testing of the discovery using real clouds in the atmosphere.

Before the end of 1946 I had found it possible to do the following things with dry ice or liquid carbon dioxide:

1) Conversion of a supercooled alto-cumulus cloud to snow crystal streamers.

2) Complete conversion of a supercooled valley fog to ice crystals followed by clearing by fallout.

3) Production of ice crystals in large numbers below the base of a convective supercooled cloud system using liquid carbon dioxide. This operation was followed by the development of a local snow storm producing 4-5 inches of snow in the Hudson and Champlain Valleys. There is no proof that the seeding caused this snow although it started within a half hour after seeding from the area where the seeding began.

4) Extensive grooves were cut into a stratus cloud deck along the line of flight.

5) Single towering supercooled cumulus were caused to produce localized snow showers.

\section{The events which led to the organization of Project Cirrus}

Early in 1947 [13], the counsel of General Electric, the company which had sponsored our research, pointed out the potential legal problems likely to confront the Company if our activities continued to develop along the line of our increasing interest. Consequently, we were forced to discontinue active field experimentation until 28 February 1947 at which time a signed contract was received from the U. S. Army Signal Corps covering "research study of cloud particles and cloud modification." This contract although administered by the Army had joint sponsorship with the Office of Naval Research with the close cooperation of the U. S. Air Force which furnished airplanes and flight personnel.

Under the terms of this contract "the entire flight program shall be conducted by the Government using exclusively government personnel and equipment and shall be under the exclusive direction and control of such government personnel."
The General Electric group represented by Dr. Irving Langmuir and Vincent Schaefer served as consultants to the Steering Committee headed by Dr. Michael Ference, Jr. This Steering Committee routinely reviewed the field operations of the Flight Operations Group headed by Commander Daniẹl F. Rex which conducted the flight studies in close consultation with the G. E. group. During the period 1 March 1947 to 30 September 1952, 225 flights were conducted for the specific purpose of establishing the possibilities as well as limitations of dry ice, silver iodide and water seeding cloud operations, the study of clouds and the testing of instruments.

\section{Vonnegut's discovery of silver iodide as a cloud nucleant}

In October 1946, Dr. Bernard Vonnegut, one of my associates at G. E., produced ice crystals in large numbers from both silver and lead iodide [14]. During the following months he devised [15] a wide variety of silver iodide smoke generators ranging from the type now almost commonly used which burns a solution of silver iodide in acetone containing either sodium or potassium iodide to a generator which burns charcoal or coke impregnated with silver iodide or a device for producing an electric spark using silver electrodes in an environment saturated with iodine vapor. Although the acetone solution is ordinarily burned in a propane or other hot flame he also made a large generator for airborne use which burned the acetone in an air blast.

\section{Langmuir's ideas on water seeding and energy release}

In 1947, Dr. Langmuir proposed [16] seeding convective cumulus clouds with relatively small quantities of water depending on the coalescence and break up of water drops to develop a chain reaction mechanism which would produce rain in warm clouds.

A year later when a convective cloud system in $\mathrm{New}$ Mexico was seeded by a Project Cirrus B-17 aircraft, he claimed that extensive rains which developed over New Mexico downwind of the seeded area had been triggered off by this initial seeding effort. The detailed analysis which he conducted [17] provides an impressive document and should be studied by those who are now interested in utilizing the energy stored in the latent heat of sublimation for developing localized convergence in a storm system.

\section{The development of widespread interest in cloud seeding}

From the time of the initial announcement of the dry ice seeding effect until Project Cirrus ended we had visits from many individuals and voluminous correspondence with interested scientists and engineers from all parts of the world. Since the General Electric Company made our patents on the dry ice and silver iodide discoveries part of the public domain we made all of our 


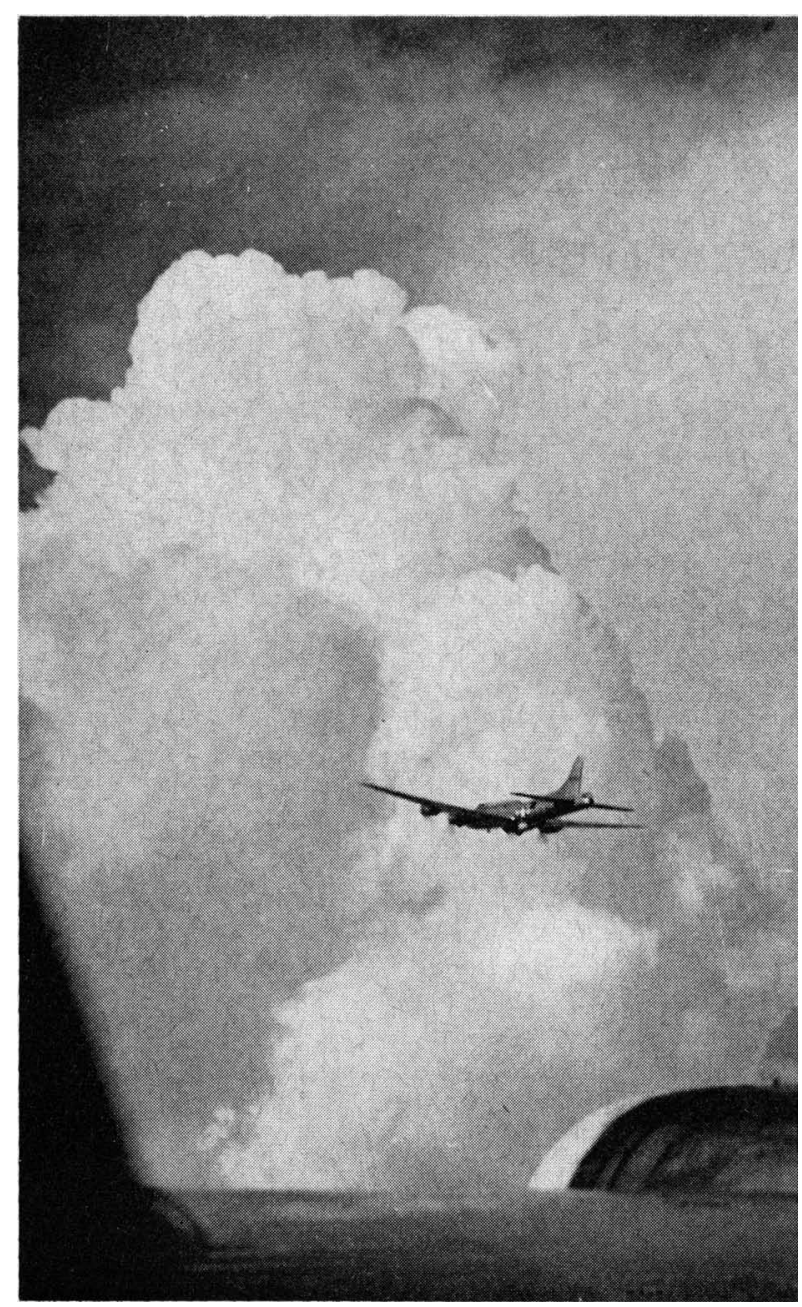

B-17 of Project Cirrus about to seed a cumulus cloud with crushed dry ice.

findings available through Quarterly [18] and Occasional Reports [19] and papers published in scientific periodicals. When Project Cirrus was terminated at our request in 1952, several Final Reports [20] were published summarizing most of the salient findings. The large quantity of photographs and flight data of Project Cirrus has been preserved and has recently been made available to the special International Library on Weather Modification being established at the State University of New York.

\section{Significant advances in cloud seeding during 1947}

The following historical references were prepared by the writer 20 years ago to summarize the salient points of progress which occurred during the year following the initial announcement of the dry ice effect. This was prepared at the request of a farmers' periodical [21].

"13 November 1946-Initial experiment by the author over Berkshires in Massachusetts, converting a four-mile supercooled strato-cumulus cloud into snow flurries using six pounds of granulated dry ice.
21 November 1946-Conversion by the author of supercooled ground fog to snow crystals by seeding with dry ice. Schenectady, New York.

20 December 1946-Production of snow by R. Smith-Johannsen in supercooled orographic cloud on summit of Mt. Washington, New Hampshire. Seeding with liquid $\mathrm{CO}_{2}$ from tower of Mt. Washington Observatory.

20 December 1946-Production of extensive snow area by the author in supercooled stratus cloud by seeding in base of supercooled overcast with dry ice and liquid $\mathrm{CO}_{2}$ in region north of Mohawk Valley in New York.

5 February 1947-E. B. Kraus and P. Squires. Production of rain in strato-cumulus by seeding supercooled cloud at $23,000 \mathrm{ft}$ with dry ice and detection of effect by radar 100 miles east of Sydney, Australia.

6 February 1947-Production of snow by R. E. Falconer and V. F. Clark in supercooled orographic cloud at $6200 \mathrm{ft}$ using silver iodide flare. Mt. Washington, New Hampshire.

4 April 1947-Col. E. S. Ellison and L. R. Richards. Production of rain in supercooled stratus cloud at $10,000 \mathrm{ft}$ in Oregon.

7 April 1947-Personnel of Project Cirrus. Joint Army-NavyAir Forces-General Electric project produced 45-sq-mi geometric hole in supercooled stratus cloud over Adirondack Mountains in New York to obtain quantitative information on effect of dry ice seeding methods.

16 July 1947-A. Hoff and H. L. Mott. Production of rain from cumulus clouds near Phoenix, Ariz., by seeding cloud at $20,000 \mathrm{ft}$ with dry ice.

23 September 1947-Production of rain at $9500 \mathrm{ft}$ by $\mathbf{L}$. B. Leopold and M. Halstead in above-freezing cumulus cloud using dry ice over island of Molokai in Hawaiian Islands. Results interpreted by Dr. Irving Langmuir as start of chain reaction in new precipitation theory advanced in paper delivered before the National Academy of Sciences, 17 November 1947.

13 October 1947-Personnel of Project Cirrus in dry ice seeding flight and cloud study of hurricane "King" 350 miles east of Jacksonville, Fla., at 25,000 ft.

September-October 1947-Production of snow and rain by C. L. Chipman and G. G. Sampson in vicinity of Prosser, Wash., in series of flights.

October-November 1947-Series of experimental flights over western Kansas by C. Barhydt and J. Berkeley, producing snow and rain areas."

\section{The termination of Project Cirrus}

With the termination of Project Cirrus and completion of the reports and scientific papers, the Project Cirrus Research Group at the G. E. Research Laboratory was disbanded. Langmuir retired from the Laboratory; Schaefer went with the Munitalp Foundation and helped establish Project Skyfire and a number of other new groups developed to do research in the Atmospheric Sciences; Vonnegut joined Arthur D. Little, Inc., as a research associate to continue his interest in atmospheric electricity with Maynard as an assistant; Blanchard 


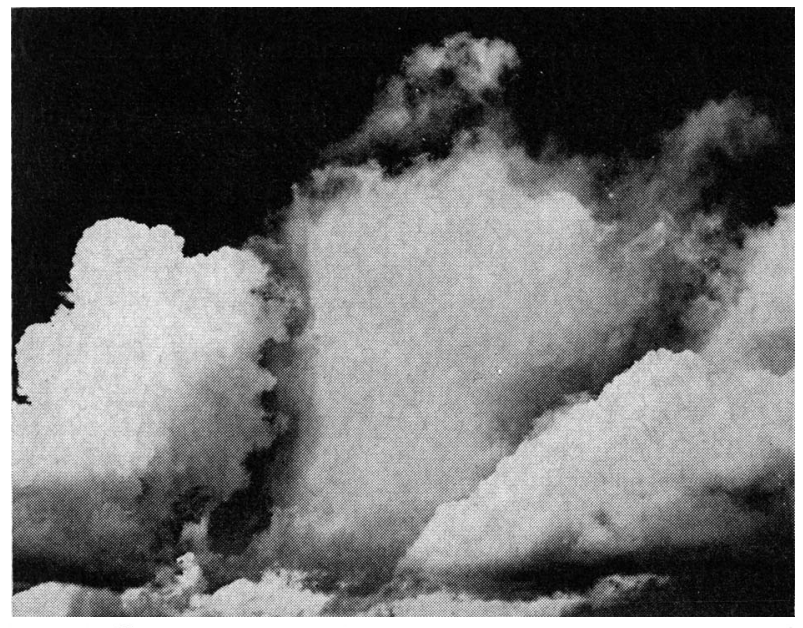

Seeding of cumulus with silver iodide. Middle cloud is seeded. Project Skyfire.

joined the Woods Hole Oceanographic Institute to study ocean-air interfacial phenomena and rain drop distribution relationship; Falconer became a Research Associate with me at Munitalp to develop his long range forecasting technique and public relations interest, while Smith-Johannsen shifted into colloid and silicone chemistry finally forming his own company.

The historical record of cloud modification activities following the first few years of Project Cirrus is well documented in the Final Report of the President's Advisory Committee on Weather Control [22], the Annual Reports of the National Science Foundation [23] and the recently issued report of the National Academy of Sciences [24].

\section{Subsequent activities of the G. E. Group}

Despite their various diversities of interest the disbanded Project Cirrus Research Group maintained a degree of contact through Adirondack Conferences [25] and other types of scientific meetings. Project Shower in the $\mathrm{Ha}$ waiian Islands in 1954 [26], studies at Mt. Withington in New Mexico and especially the Yellowstone Field Research Expeditions [27] from 1961 to the present and several intensive international conferences were responsible for a degree of continuity that served to bring the group together for enjoyable and scientifically productive periods.

\section{The reunion of the $\mathrm{G}$. E. Group}

Finally during the past year arrangements were completed for Schaefer, Falconer, Vonnegut and Blanchard to work together again as part of the Atmospheric Sciences Research Center of the State University of New York at Albany.

Although earlier interests still play an important role in their research studies, all four have greatly widened the range of activities and accordingly a wide variety of subjects now challenge the ability of their students.

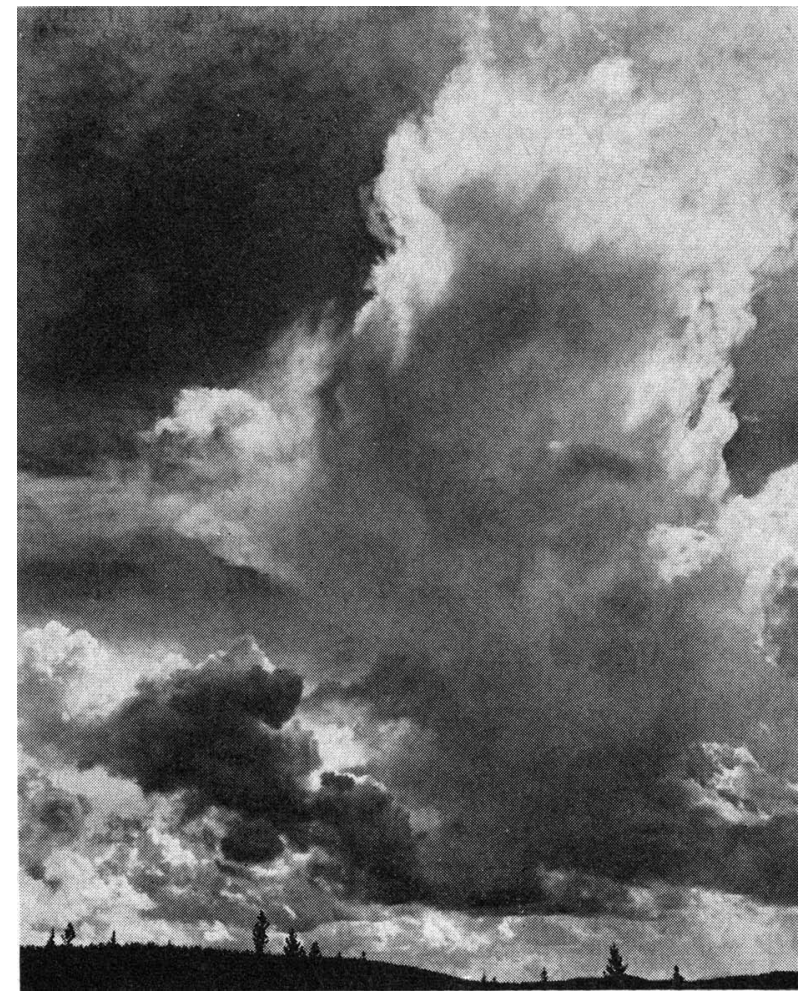

Typical example of effective cumulus cloud overseeding observed during 1958 Project Skyfire-29 July 1958.

An interesting feature of our current research activity within the University utilizes the million cubic foot hangar formerly used by General Electric at the Schenectady County Airport for their flight test activities. It was in the control tower at this location where Langmuir was stationed when he witnessed Schaefer's original field experiment and where Project Cirrus was headquartered during most of its productive life. This facility now contains a fogchamber of 5000 cubic meters, cloud charging devices and a very large vertical wind tunnel is under construction for hail studies.

\section{The current program of research at Albany and Schenectady}

The Atmospheric Sciences Research Center and the Department of Atmospheric Sciences at Albany now has more than 20 research-oriented professors and scientists. With the excellent group of students now studying in the University at Albany, we anticipate another active and exciting period of productive research in weather modification and related subjects over the next decade. Our concern at present is strongly oriented toward inadvertent weather modification [28, 29, 30] and its related scientific and engineering problems. While the possible role played by air pollution on weather patterns was dimly perceived in 1946, the proliferation of automobiles, the vast fleet of jet aircraft and the continuing demand to utilize more and more of the grass lands of the high plains and other places all com- 
bine to pose a most serious proliferation of the number of cloud and ice nuclei in the air over the United States. The role these particles play in atmospheric weather modification needs to be studied in detail. Our present work is concerned in part with the lead from automobile exhaust being converted to the lead iodide type of ice nuclei, the effect of ice crystals from jet condensation trails on the weather along flight routes and the airborne dust from the dry fields of the Great Plains.

\section{References}

1. Gathman, L., 1891: Method of producing rainfall. U. S. Patent Office, Patent No. 462,795, Nov. 10.

2. Veraart, A. W., 1931: More sunshine in the cloudy North, more rain in the tropics. Amsterdam N.V. Seyfardts Boek and Muziekhandel.

3. National Academy of Sciences-National Research Council, 1966: Weather and Climate Modification Problems and Prospects. Final Report Publication No. 1350, Washington, D. C.

4. Schaefer, V. J., 1946: The production of ice crystals in a cloud of supercooled water droplets. Science, 104, $457-459$.

5. Findeisen, W., 1938: Colloidal meteorological processes in the formation of atmospheric precipitation. Meteor. Z., 55, p. 121-133.

6. Schaefer, V. J., 1960: Serendipity and the development of experimental meteorology. J. Irrig. and Drain Div. Proc. of the Amer. Soc. Civil Eng., 86, 1-16.

7. Langmuir, I., and V. J. Schaefer, 1937: The effect of dissolved salts on insoluble monolayers. J. Amer. Chem. Soc., 59, 2400-2414.

8. Langmuir, I., 1948: The growth of particles in smokes and clouds and the production of snow from supercooled clouds. Proc. Amer. Phil. Soc., 92, 167-176.

9. Schaefer, V. J., 1947: Properties of particles of snow and the electrical effects they produce in storms. Trans. Amer. Geophys. Union, 28, 587-614.

10. Schaefer, V. J., 1946: Final report on icing research up to July 1, 1946. G. E. Res. Lab. ATSC Contract W-33-038AC-9151, 45 pp.

11. Schaefer, V. J., 1941: A method for making snowflake replicas. Science, 93, 239-240.

12. Schaefer, V. J., 1941: A method of making replicas of snowflakes, ice crystals and other shortlived substances. The Museum News, 19, 11-12.

13. Havens, B. S., 1952: Project Cirrus-the story of cloud seeding. G. E. Rev., 8, 26.

14. Vonnegut, B., 1947: The nucleation of ice formation by silver iodide. J. Appl. Phys., 18, 593-595.

15. Vonnegut, B., 1947: Silver iodide smoke. Occasional Report No. 13, General Electric Research Laboratory Publication RL 140, Schenectady, N. Y.
16. Langmuir, I., 1948: The production of a chain reaction in cumulus clouds at temperatures above freezing. $J$. Meteor., 5, 175-181.

17. Langmuir, I., 1950: Results of the seeding of cumulus clouds in New Mexico. Project Cirrus Occasional Report No. 24, General Electric Research Laboratory Publication No. RL 364, Schenectady, N. Y., 20 pp.

18. Schaefer, V. J., and others, 1947-52: (A series of 19 quarterly reports on cloud physics and experimental meteorology). Project Cirrus Contract No. W-36-039SC-32427, G. E. Res. Lab., Schenectady, N. Y.

19. Schaefer, V. J., and others, 1947-52: (A series of 40 occasional reports on cloud physics and experimental meteorology). Project Cirrus Contract No. W-36-039-SC32427, G. E. Res. Lab., Schenectady, N. Y.

20. Schaefer, V. J., 1953: Final report Project Cirrus, Part I laboratory, field and flight experiments. Contract No. DA-36-039-SC-15345, G. E. Res. Lab. No. RL-785, Schenectady, N. Y., 170 pp.

Langmuir, I., 1953: Final report Project Cirrus, Part II analysis of the effects of periodic seeding of the atmosphere with silver iodide. Contract No. DA-36-039SC-15345, G. E. Res. Lab. No. RL-785, Schenectady, N. Y., 340 pp.

Schaefer, V. J., 1953: Final report ONR Project. Contract No. NONR-925(00), G. E. Res. Lab. No. RL-1007, Schenectady, N. Y., 103 pp.

21. Schaefer, V. J., 1948: The story of man-made weather. Amer. Fruit Grower, 68, No. 3, 17-43.

22. Final report Advisory Committee on Weather Control, 1957: Part I \& II, Washington, D. C., Supt. of Documents, Govt. Printing Office, 422 pp.

23. Annual reports on weather modification. National Science Foundation (1959-present), Supt. of Documents, Govt. Printing Office.

24. National Academy of Sciences-National Research Council, 1966: Weather and Climate Modification Problems and Prospects. Final Report Publication No. 1350, Washington, D. C., 198 pp.

25. Schaefer, V. J., 1957: The Adirondack conference. Bull. Amer. Meteor. Soc., 38, 550-551.

26. Schaefer, V. J., 1956: Atmospheric measurements in the Hawaiian Islands. Rev. Geofisica Pura e Appl., 34, 209219.

27. Schaefer, V. J., 1961-1967: Yellowstone field research expedition annual reports. Atmospheric Sciences Research Center Pub. No. 1, 5, 13, 22, 31, 37, 45, State University of New York at Albany.

28. Schaefer, V. J., 1966: Ice nuclei from automobile exhaust and iodine vapor. Science, 154, 1555-1557.

29. Schaefer, V. J., 1968: Ice nuclei from automobile exhaust and organic vapors. J. Appl. Meteor., 7, 148-149.

30. Hogan, A., 1967: Ice nuclei from direct reaction of iodine vapor with vapors from leaded gasoline. Science, 158, 800 . 